\title{
Iron deficiency in pernicious anaemia: a neglected diagnosis
}

\author{
H.I. Atrah and R.J.L. Davidson \\ Haematology Unit, Medical School, Foresterhill, Aberdeen AB9 2ZD, UK
}

\begin{abstract}
Summary: In 114 patients (52 males and 62 females) with long-standing pernicious anaemia, hypoferritinaemia was found in $27(23.7 \%)$ and hypochromic microcytic anaemia in $19(16.6 \%)$. Our findings indicate that iron deficiency is a common yet neglected complication of long-standing pernicious anaemia and warrants greater diagnostic and therapeutic attention.
\end{abstract}

\section{Introduction}

Addisonian pernicious anaemia (PA) is an autoimmune disorder characterized by gastric mucosal atrophy, progressive intrinsic factor (IF) hyposecretion and achlorhydria. Because of the latter, impairment of iron absorption is a likely consequence. However, screening and preventive measures for iron deficiency in patients with PA are commonly overlooked. This study was undertaken to establish the frequency and severity of iron deficiency in a group of patients with longestablished PA.

\section{Patients and methods}

One hundred and fifty patients with a definitive diagnosis of PA made within the last 10 years were identified from the medical records of Aberdeen Royal Infirmary. Validation of the diagnosis of PA was based on all or a combination of the following criteria: a low serum $B_{12}$, unequivocal megaloblastic bone marrow, serum IF antibody, $B_{12}$ malabsorption (Schilling or Dicopac test) and a satisfactory response to parenteral $B_{12}$ medication. Clinical and laboratory details including haemoglobin level at diagnosis, the duration of the disease and its subsequent management were documented. The general practitioners of those studied were asked to complete a questionnaire detailing clinical information including that of vitamin $\mathbf{B}_{12}$, iron and folic acid therapy and to obtain clotted and anticoagulated $\left(\mathrm{K}_{2}\right.$ EDTA) samples for the following haematological analyses: peripheral blood profile

Correspondence: H.I. Atrah, M.R.C.P.

Accepted: 3 September 1987
(Coulter S plus IV) and film microscopy; serum ferritin and red cell folate (RCF) levels (radioassays, Becton-Dickinson, Immunodiagnostics, New York).

Blood samples were received from 52 males (mean age 67.3 years) and 62 females (mean age 66.9 years). The mean haemoglobin level at diagnosis of PA was $99 \mathrm{~g} / 1$ (range 38-147) and mean duration of disease from diagnosis 70 months (range 14-137). Although the diagnosis had been initially established in hospital only $21 \%$ were 8 subsequently reviewed annually at an outpatient clinic. All patients were receiving hydroxocobalamino (Neocytamen) in a dose ranging from $250-1000 \mu \mathrm{g}$ ? and at intervals of between 2 weeks and 3 months. The majority $(69.2 \%)$ were receiving $1000 \mu \mathrm{g} /$ month. Oral iron in unspecified amounts had been prescribed for only 5 males and 16 females during the previous 2 years. Oral folic acid was being additionally taken by 2 males and 2 females.

\section{Results}

In 52 males, anaemia (haemoglobin $<135 \mathrm{~g} / \mathrm{l}$ ) of variable severity (mean 110 , range $55-134 \mathrm{~g} / \mathrm{l}$ ) was found in $15(28.8 \%)$ and based on film microscopy, mean cell volume and mean cell haemoglobin was adjudged to be of a hypochromic microcytic type in 10 and normochromic and normocytic in 4. In one, the anaemia was frankly macrocytic (haemoglobin $55 \mathrm{~g} / \mathrm{l}$, mean cell volume $121 \mathrm{fl}$ and serum $\mathrm{B}_{12}$ $50 \mathrm{ng} / \mathrm{l})$ due to discontinuation of speeific therapy for one year. In 62 females, anaemia (haemoglobin $<120 \mathrm{~g} / \mathrm{l}$ ) generally mild (mean 111 , range 99-118 g/l) was found in $12(19.4 \%)$ being of hypochromic microcytic type in 9 and normochromic normocytic in 3 . Significant hypo-ferritinaemia ( $<16 \mathrm{ng} / \mathrm{ml}$ in males and $<12 \mathrm{ng} / \mathrm{ml}$ in females)

(C) The Fellowship of Postgraduate Medicine, 1988 
was found in 11 males $(21.2 \%)$ and 16 females $(25.8 \%)$. Of these 27 patients only 19 had an accompanying hypochromic microcytic anaemia, 4 had a normocytic normochromic anaemia and 4 had no anaemia. It is noteworthy that the female group included 5 patients who had received recent, but apparently inadequate, oral iron therapy. RCF was subnormal $(125 \mu \mathrm{g} / \mathrm{l})$ in one patient only.

The current haemoglobin and serum ferritin levels were not statistically influenced by the haemoglobin level recorded at initial diagnosis, the duration of the disease or the review mechanism.

\section{Discussion}

While evidence has been conflicting, ${ }^{1}$ it is now generally accepted that histamine-fast achlorhydria is associated with impaired iron absorption ${ }^{2}$ and that both the acid and peptic enzyme components are of importance. ${ }^{3}$ Iron deficiency may, therefore, be expected to develop in patients with longstanding PA.

The unmasking of iron deficiency following the commencement of vitamin $B_{12}$ therapy for PA is consistently emphasized in related literature,${ }^{4}$ but the predisposition to the late development of iron deficiency in such patients receives scant attention. We have traced only one reference ${ }^{5}$ to such a study and that indicated 56 of 138 patients with PA developed iron deficiency at some stage following the first year of treatment and that in 43 there was no detectable source of blood loss.

In this study, serum ferritin concentration, currently regarded as the best index of storage iron, ${ }^{6}$ was found to be low in $23.7 \%$ of our patients despite a significant number (18.4\%) having had oral iron prescribed within the previous two years. We found no aetiological relationship between the current iron status as reflected by serum ferritin and haemoglobin level at diagnosis $(r=0.061)$ or duration of the disease $(r=0.037)$ although these probable associations may have been obscured by iron randomly administered to some of the patients.

We emphasize that while iron deficiency in patients under treatment for PA may simply signify long-standing iron malabsorption, it is imperative to exclude a source of chronic blood loss, particularly in the gastrointestinal tract as it has been long recognized that both PA and atrophic gastritis predispose to carcinoma as well as carcinoid of the gastric mucosa. $^{7}$

In conclusion, our findings indicate that iron deficiency is a common complication in patients with long-standing PA and that its diagnosis and treatment are commonly neglected. We strongly recommend that all patients with PA be routinely reviewed at least annually by their family doctor or at their outpatient clinic and this should include full peripheral blood examination and a test to assess iron status preferably by serum ferritin assay. ${ }^{6}$ Because of the likelihood of suboptimal iron absorption, especially in the elderly, it is further suggested that the use of parenteral iron be more frequently considered. Finally, following initial intensive treatment with hydroxocobalamin a maintenance schedule of $1000 \mu \mathrm{g}$ every 3 months is recommended along with the peremptory step of explaining and emphasizing to the patient the need for life-long treatment and regular attendance at follow-up appointments.

\section{References}

1. Editorial. Iron absorption. Scot Med J 1963, 8: 366-369.

2. Goldberg, A., Lochhead, A.C. \& Dagg, J.H. Histamine-fast achlorhydria and iron absorption. Lancet 1963, i: 848-850.

3. Jacobs, A. The mechanism of iron absorption. Clin Haematol 1973, 2: 323-338.

4. Chanarin, I. The Megaloblastic Anaemias. Blackwell Scientific Publications, Oxford, 1979, pp 230-262.

5. Gibson, I.J.M., Kelly, A.M. \& Wang, I. The iron deficiency of pernicious anaemia. Scot Med J 1963, 8: 357-364.

6. Jacobs, A. \& Worwood, M. Assessment of iron stores, Assoc Clin Pathol Broadsheet 111, 1984.

7. Elsborg, L. \& Mosbech, J. Pernicious anaemia as a risk factor in gastric cancer. Acta Med Scand 1979, 206: $315-318$. 